\title{
UK records four cases of Zika virus in past six weeks
}

\author{
Adrian O'Dowd
}

London

Four cases of people infected with the Zika virus have been confirmed in the United Kingdom since the start of this year, experts have told MPs.

These cases may have come to light because of the recent focus on a large rise in infections in Brazil, experts told MPs on the House of Commons science and technology committee during a one-off evidence session on 10 February looking at the Zika virus.

Since last October, Brazil has reported around 1.5 million cases of the Zika mosquito-borne virus and 4000 suspected cases of microcephaly - the condition that leads to babies being born with underdeveloped brains - and fears have arisen about a possible link between the two. On 1 February, the World Health Organization declared a global public health emergency over the virus. ${ }^{1}$

One of the public health experts giving evidence to the committee said that the United Kingdom had recorded a small number of Zika cases recently.

Dilys Morgan, head of gastrointestinal, emerging, and zoonotic infections at Public Health England, said, "We have had seven cases, six associated with this current outbreak in South America, in the past three years.

"We have four of those in 2016, so we are seeing cases coming back. We have raised awareness so that people are more aware of the infections. We are likely to see more cases."

The recent cases were "travel associated" and were not believed to have been contracted in the UK, the committee heard.

A fellow witness was Alain Kohl, programme leader at MRC University of Glasgow Centre for Virus Research, who said,

"The risk to the UK public is extremely low and mainly a risk resulting from travel to affected countries and bringing viruses back."

MPs asked whether any scientific evidence showed a clear link between Zika and babies being born with microcephaly. The expert witnesses said that no such clear link had been found, and Kohl added, "One of the reasons we don't know much about Zika is because it has never really been studied in the past. What has happened in Brazil may be a novelty, but it may not, so studies need to be done.

"There are various possibilities why microcephaly is on the rise - it could be viral or genetic — the mechanisms are very poorly understood. We have circumstantial evidence, which is, although mounting, not entirely conclusive."
Morgan said that, of the 400 confirmed cases of microcephaly in Brazil, Zika virus infection had been proved in only 17 of those infants, adding, "We don't really know what proportion of births are affected by Zika or what defects are caused by Zika if, indeed, they are. It is difficult to prove virologically that those infants' defects were caused by Zika."

The need for rapid research into the virus to find a vaccine was discussed during the session, and Graeme Tunbridge, deputy director for emergency preparedness, resilience, and response at the Department of Health, also giving evidence, said that preparatory work was under way. For example, a governmental pre-SAGE (Scientific Advisory Group for Emergencies) meeting had taken place last week about the issue, chaired by Mark Walport, government chief scientific adviser, and Chris Whitty, Department of Health chief scientific adviser.

Tunbridge said, " [The meeting] brought together scientists with the relevant expertise to look at understanding the evidence base and the current science and also a focus on the risks to the UK. I imagine there will be another pre-SAGE in the next couple of weeks to start to think about the more international research questions."

To help develop a vaccine, the government has already given $£ 400000$ ( $€ 511000 ; \$ 578000$ ) funding to Kohl's department at the University of Glasgow through the Newton Fund, an initiative intended to strengthen research and innovation partnerships between the UK and emerging knowledge economies.

MPs asked whether the UK was doing enough, given that the US president, Barack Obama, had recently announced that his country would give $\$ 1.8 \mathrm{bn}$ ( $£ 1.25 \mathrm{bn}$; $€ 1.59 \mathrm{bn}$ ) to fight the Zika virus, which would include research into developing a vaccine. Peter Horby, of the Centre for Tropical Medicine and Global Health at the University of Oxford, also giving evidence, replied, "Significant investment is needed, and Obama's $\$ 1.8 \mathrm{bn}$ is a fantastic investment.

"What we are seeing is that there has been investment into UK science and what we can bring to the table, but I still think it could be quicker. On the research side, what we need is faster turnover."

1 Gulland A. Zika virus is a global public health emergency, declares WHO. BMJ 2016;352:i657. 